\title{
Influence of the rootstock variety on the vegetative and uvological measures of grapes
}

\author{
Natalia Pavlyuchenko ${ }^{1, *}$, Natalia Zimina ${ }^{1}$, Svetlana Melnikova ${ }^{1}$, and Olga Kolesnikova ${ }^{1}$ \\ ${ }^{1}$ All-Russian Scientific and Research Institute of Viticulture and Winemaking named after Ya.I. \\ Potapenko - branch of the Federal State Budget Scientific Institution Federal Rostov Agricultural \\ Scientific Centre (VNIIViV named after Ya.I. Potapenko), 346421, 166 Baklanovskiy avenue, \\ Novocherkassk, Rostov region, Russia
}

\begin{abstract}
The goal of research - signification of influence of the genotype of rootstock varieties on the vegetative and reproductive characteristic of the Purple early (Fioletoviy ranniy) grafted grape variety during adaptation in the field. Observations of research was made with using rootstock varieties - PP 101-14, Kober 5BB, Vierul-3. The influence of the rootstock genotype was introduced on the basis of by the survival rate of bushes, plant growth characteristics of the Purple early (Fioletoviy ranniy) variety, and uvological properties. The least death of bushes was found by usage the rootstock Vierul -3 . Was revealed influence of the rootstock genotype on the vegetative measures of the grafted variety. The genotype of the Vierul - 3 rootstock variety was materially affected the leaf-area and leaf-area duration of the bush. Was found that influence of rootstock on the reproductive properties of graft - rootstock combinations. Grafting on the rootstock Cober 5BB foster the increase slightly of yield per Bush. Uvology indicators point at a positive effects of rootstock Vierul-3 on the weight of cluster and berries, the size of cluster and berries, the structure and form of the cluster and total sugars. On-farm research of agrocenosis, is advisable to graft the rootstock Vierul-3 for Fioletoviy ranniy variety.
\end{abstract}

\section{Introduction}

Grapes, like most agricultural crops, are affected by biotic and abiotic factors that change the vegetative and generative processes, plant productivity and product quality. The factor that had a considerable influence on the development of winegrowing was the spread of plant pests of phylloxera. The origin of a native to North America, it is introduced to Europe with planting material in the later of the 19th century. On the Vineland of the Lower Don region, phylloxera spread in the later of 20th century. At present time, in most winegrowing regions, Vitis vinifera varieties massing its possible only by grafting on phylloxera-resistant rootstocks of American origin and their hybrids. About $80 \%$ of the world's Vineland is planted with bench grafted rootings [1]. Research programs in all winegrowing regions are designed to produce on studying the interaction of graft -rootstock

\footnotetext{
* Corresponding author: npavlyuchenko@yandex.ru
} 
combinations. As a result of research was found of resistance to phylloxera and nematodes, and also had a strong effect on rootstocks affect the compatibility of grafted components [2], the adaptation of the cultigen to environment, is highly topical issue in a changing climate. The different ability of rootstocks to absorb nutritional chemicals and moisture [3], xerophytism and salt resistance [4] are reflected in the vegetative growth of the grape bush and the accumulation of biomass [5], the passage of phenological phases of growing [6,7], yield $[8,9]$, the nutrient content in plants organs [10 - 12]. Depending on the variety of rootstock, changes the chemical composition of berries (acidity, sugar degree, content of phenolic substances, etc.) $[13,14]$, which affects the quality of wine and determines its distinctive character, which is directly related to the genetic material of the variety, cultivation methods adopted in the vineyard, and the viticulture ecosystem [15 - 17]. In order to determine the effect of rootstock, exploring was conducted on Vitis vinifera L. varieties, which comprise the backbone of the assortment of European countries. For the zone of covering viticulture, varieties of interbreeding obtained with the Vitis amurensis (Maxim.) very important, but without resistant to phylloxera. The spread of phylloxera in the Northern regions at a later time caused the relatively late development of the grafted culture in the Lower Don region. In this regard at present time, research of compatibility scion-rootstock combinations, grafting affinity, longevity and productivity of grafted plantings is currently of great importance.

This study was focused on scientific scrutiny the influence of the genotype of rootstock varieties on the vegetative and reproductive characteristics of the Fioletoviy ranniy graft variety during adaptation in the field conditions of the Northern winegrowing.

\section{Materials and methods}

\subsection{Biomaterial}

In research used rootstock varieties: Riparia x Rupestris 101-14, Berlandieri x Riparia Kober 5BB, Vierul-3 (Coarna nyagre x Riparia Gluar).

Graft variety Fioletoviy ranniy (Northern (seedling Malengra x V. amurensis) x Muscat Hamburg) - interspecific hybrid. The processing crop is used for making various types of wine. When grown on own-root culture, the clusters are medium-sized, conical, and loose, the mass of the cluster is $130 \ldots 180 \mathrm{~g}$ (Fig. 1). The berries are glomerate, dark purple. The savour has a pronounced nutmeg flavor. Bushes of average growth strength, shoots ripening is well $(80 \ldots 90 \%)$.

\subsection{The conditions of the experiment}

The experiment was conducted in field conditions in ASRIViW named after Ya.I. Potapenko branch FSBSI FRASC, (Novocherkassk, Rostov region) for 2007-2018 years. The experimentation in the spring of 2007 year. The experimental pilot site was planted with annual grafted rootings in triplicate of 10 bushes of each rootstock genotype. The planting system is $3,0 \times 1,0 \mathrm{~m}$. The shaped bush is a double-lever horizontal cordon with a vine trunk of $0,5 \mathrm{~m}$. The culture open-earth and without irrigation. The technology of cultivation of vineyards is mainstream technology for the Northern zone of grape industry in Russian Federation. 


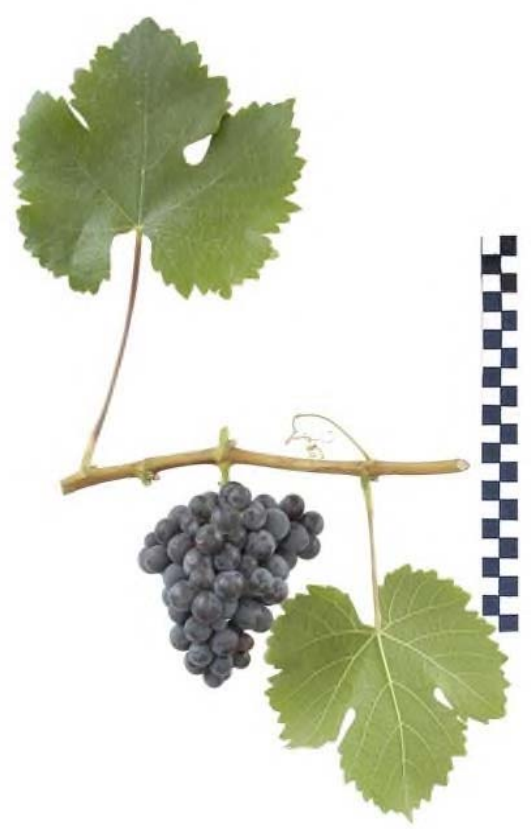

Fig. 1. Ampelographic image of a bunch of Fioletoviy ranniy variety

\subsection{Climatic parameter}

The climatic parameter during the experiment were typical for city Novocherkassk. The climate is continental. The accumulated positive temperatures average-per-day from the third decade of April until to occurrence of frost $3300-3400^{\circ} \mathrm{C}$. The area belongs to the zone of subhumid, the annual precipitation is $530 \mathrm{~mm}$. Meteorological conditions were monitored using a meteorological observing station located on the same experimental field.

\subsection{Soil conditions}

Soil type-ordinary chernozem, carbonated, medium thickness seam, heavy loam, loess loam. The nutrient-supplying capacity in the tilth top soil are characterized by the following values: mobile phosphorus - $3,27 \mathrm{mg} / \mathrm{kg}$, exchangeable potassium $-591,6 \mathrm{mg} / \mathrm{kg}$, nitrates $40,72 \mathrm{mg} / \mathrm{kg}$. The humusness is $5,2 \%$. Groundwater occurrence is a deep on the border between the native rock and calcic horizon and does not affect the development of the root system of the grape.

\subsection{Research Methods}

\subsubsection{Plant conservation Accounting}

Plant conservation Accounting was carried out in the spring - after the budding and autumn by estimating of live plants.

\subsubsection{Plant Growth}


At the end of the growing season made a record of the number of leaves (pcs.) determine the area of one leaf and leaf-area duration $\left(\mathrm{cm}^{2}\right)$, length of shoots $(\mathrm{cm})$, diameter of shoots $(\mathrm{mm})$, assessment of aging annual shoots (\%) on all of record bushes. The average shoot length $(\mathrm{cm})$ counted by the ratio of the sum of the length of the shoots of each plant to the total shoots. The leaf-area duration and one leaf was evaluated by the ampelometric method. The ripeness of annual shoots was determined by morphological characteristics.

\subsubsection{Crop Uvological assessment}

The crop estimate was carried out to the common method of varieties by A. M. Lazarevsky (1963). Crop accounting was carried out when the technical ripeness of berries. The average weight of bunches $(\mathrm{g})$ was determined by the reckoning by ratio of the yield per bush to the number of bunches, the average weight of the berries - by ratio of the aggregate weight of $100 \mathrm{pcs}$. berries per the number of berries, average berry size $(\mathrm{mm})-\mathrm{a}$ measuring of 25 pcs. berries, the size of the clusters $(\mathrm{cm})-$ a measuring of the 10 clusters. The total sugars $\left(\mathrm{g} / \mathrm{dm}^{3}\right)$ and organic acidity $\left(\mathrm{g} / \mathrm{dm}^{3}\right)$ in berry juice was determined when the technical ripeness of berries. The total sugar was determined by a Refractometer, and the organic acidity content was determined by titration of $0.1 \mathrm{~N} \mathrm{NaOH}$ over phenolphthalein.

\subsection{Statistical data analysis}

Statistical processing was performed using the Excel table processor.

\section{Results and Discussion}

To application compatibility of scion-rootstock steam in the field is a number of indicators are used, including sparseness of stand, bush growth parameters, resistance to biotic and abiotic factors, yield, and uvological properties of the variety.

Sparseness of stand has a direct impact on the yield of grape plantings and it is economically feasible to reduce losses by eliminating it. In vineyards planted with grafted, the death of bushes most often occurs from incompatibility of the scion and rootstock and sparseness is one of the main indicators of interinfluence of rootstock and scion varieties in a certain agrocenosis. As a result of long-term observations, variations in the behavior of grafted bushes associated with the rootstock variety were noted. Over the entire observation period, the maximum death of Fioletoviy ranniy bushes was recorded on the rootstock of Kober 5BB and amounted to 30,9\%. The loss of bushes was noted throughout the entire observation period (Fig. 2). On the rootstock of PP 101-14 was died 27,6\% of plants 


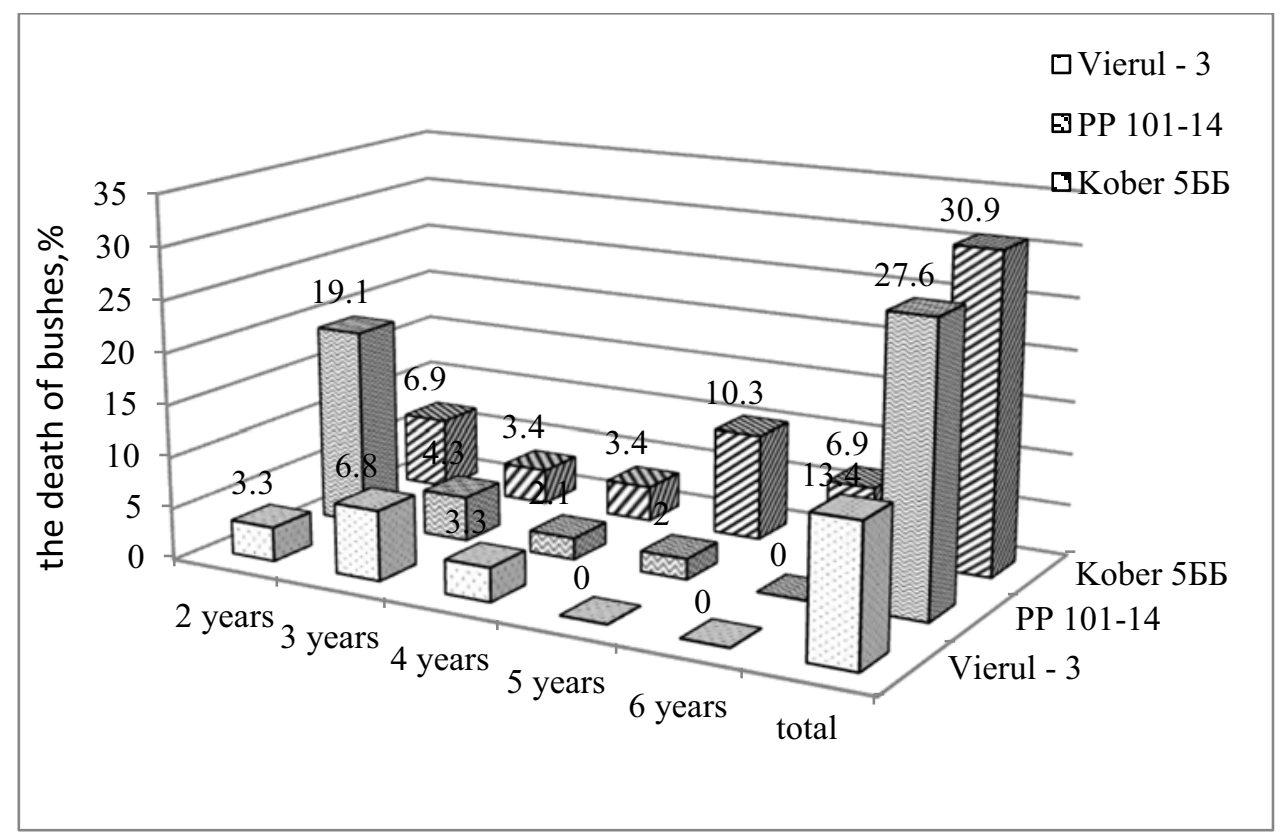

Fig. 2. Dynamics of death of Fioletoviy ranniy bushes

of which $19,1 \%$ lost the next year after planting. In the following years, the number of dead bushes was reduced materially. The minimum loss of bushes was noted on the Vierul - 3 rootstock-13,4\%, the main loss was observed the next year after planting ( $\operatorname{LSD}_{05}-5,37$ ).

Analysis of biometric indicators point out of dependence of the development of bushes on the rootstock variety. Due to the different number of shoots formed on the bush, the total length of shoots varies: on the rootstock PP 101-14, the growth gain was 18,3 m, Kober 5 $\mathrm{BB}$ and Vierul-3 - 16,7 $\mathrm{m}$ (table 1).

Table 1. Biometric measures of the Fioletoviy ranniy variety (average measures on 5-6 years of development)

\begin{tabular}{|l|c|c|c|c|}
\hline \multicolumn{1}{|c|}{ Measures } & \multicolumn{3}{|c|}{ Rootstock } & \multirow{2}{*}{$\begin{array}{c}\text { Coefficient of } \\
\text { variation (V\%) }\end{array}$} \\
\cline { 2 - 4 } & Kober 5BB & PP 10114 & Vierul - 3 & 10,0 \\
\hline $\begin{array}{l}\text { Number of shoots per bush, } \\
\text { pcs. }\end{array}$ & 10 & 11 & 9 & 5,4 \\
\hline $\begin{array}{l}\text { The total growth of the bush, } \\
\mathrm{m}\end{array}$ & 16,7 & 18,3 & 16,7 & 5.6 \\
\hline $\begin{array}{l}\text { The average length of scion, } \\
\mathrm{cm}\end{array}$ & 167 & 172 & 186 & 2,0 \\
\hline The maturation of scion, \% & 70,1 & 72,7 & 70,4 & 3,1 \\
\hline The diameter of the scion, mm & 6,3 & 6,7 & 26,6 & 26,6 \\
\hline $\begin{array}{l}\text { Number of leaves per plant, } \\
\text { pcs. }\end{array}$ & 249 & 365 & 27 & 14,7 \\
\hline $\begin{array}{l}\text { Number of leaves per scion, } \\
\text { pcs. }\end{array}$ & 25 & 33 & 34029 & 6,5 \\
\hline $\begin{array}{l}\text { Leaf-area duration of the } \\
\text { bush, cm }\end{array}$ & 32309 & 29891 & 150 & 28,9 \\
\hline Leaf area, $\mathrm{cm}^{2}$ & 129 & 82 & & \\
\hline
\end{tabular}

The condition of the bushes point out of influence of the Vierul -3 rootstock on the formation of green matter - the development of shoots and leaf surface significantly exceeds the indicators of plants on the rootstocks of Kober 5BB and PP 101-14. Bushes on the rootstock Vierul-3 are characterized by more powerful growth and larger one leaves. 
There was a significant variation in individual indicators: the number of leaves per plant the coefficient of variation comprised $26,6 \%$ and leaf-area $-28,9 \%$. However, the coefficient of variation in the number of leaves per shoot is average $-14,7 \%$. The coefficients of variability of other vegetative according are insignificant and point out of a minor influence of the rootstock variety on the parameters of the development of the graft variety.

Is a great importance for the Northern zone of grape industry, had the preparation of plants for the dormant period because a high quality of maturation of annual scion contributes to better growth and development of the grape bush and creates the optimal conditions for increasing winterhardiness and yield. The maturation of scion in the explored varieties was quite high and reached $70,1 \ldots 72,7 \%$.

The influence of the rootstock variety on the reproductive properties of the scion variety was established. Grafting on the rootstock of Kober 5BB allowed to slightly increasing the yield from the bush to $2,6 \mathrm{~kg}$ (table 2). The Vierul - 3 rootstock had a positive effect on some of quantitative characteristics - the average mass and size of the cluster, the mass and size of the berry. The influence of rootstock on the shaped and structure of the cluster are noted. On the rootstock of Vierul-3 variety, clusters of conical shaped and denser structure develop, on the rootstock of PP 101-14, the clusters are looser.

Table 2. Uvological characteristics of the Fioletoviy ranniy variety

\begin{tabular}{|l|c|c|c|c|}
\hline \multirow{2}{*}{ Measures } & \multicolumn{3}{|c|}{ Rootstock } & $\begin{array}{c}\text { Coefficient of } \\
\text { variation (V\%) }\end{array}$ \\
\cline { 2 - 4 } & Kober 5BB & PP 10114 & Vierul - 3 & 4,7 \\
\hline Yield per bush, kg & 2,6 & 2,4 & 2,4 & 7,5 \\
\hline $\begin{array}{l}\text { The number of clusters } \\
\text { on the bush, pcs. }\end{array}$ & 16,0 & 16,0 & 14,0 & 7,3 \\
\hline $\begin{array}{l}\text { The average weight of } \\
\text { bunches, } \mathrm{g}\end{array}$ & 166 & 152 & 176 & 2,3 \\
\hline Bunch length, cm & 10,6 & 11,1 & 10,9 & 8,7 \\
\hline Width of bunches, cm & 11,3 & 12,9 & 13,4 & 26,2 \\
\hline The content of stem, \% & 4,5 & 5,5 & 7,5 & 7,2 \\
\hline Berry weight, g & 2,3 & 2,3 & 2,6 & 3,0 \\
\hline Berry length, mm & 14,5 & 14,9 & 15,4 & 2,7 \\
\hline $\begin{array}{l}\text { The width of the berries, } \\
\text { mm }\end{array}$ & 14,4 & 14,7 & 15,2 & 2,8 \\
\hline Total sugars, $\mathrm{g} / \mathrm{dm}^{3}$ & 204 & 204 & 214 & 6,5 \\
\hline Total acidity, g/dm & 3,2 & 3,0 & 3,4 & \\
\hline
\end{tabular}

Considerable variability of measures that characterize the uvological characteristics of the Fioletoviy ranniy variety was noted only in the content of stem (V 26,2\%). The coefficient of variation of other characteristics ranged in the interval of $2,3 \ldots 8,7 \%$, point out of a negligible influence of the rootstock on the quantitative characteristics yield.

The maximum value of total sugars in the juice of berries was noted on the rootstock Vierul-3 - $214 \mathrm{~g} / \mathrm{dm}^{3}$. Total sugars on rootstocks PP 101-14 and Kober 5 BB was $204 \mathrm{~g} /$ $\mathrm{dm}^{3}$. The influence of the rootstock to a lesser extent affected the total of acids in the juice of berries.

\section{Conclusions}

In accordance with the obtained results obtained, the influence of the genotype of the rootstock variety on the vegetative and reproductive condition of the Purple early (Fioletoviy ranniy) graft variety was established. In the considered edaphic-climatic zone, the best measures of bush safety, biomass formation, and individual uvological characteristics of the Purple early (Purple early (Fioletoviy ranniy) variety were established when using Vierul-3 rootstock variety for grafting. A slight increase in bush productivity 
was noted on the Kober 5BB rootstock variety. The absence of a common behavior model for scion-rootstock combinations point out of the need of accurate assessment of the measures of each rootstock variety for each zone and variety, in order to select the most appropriate combination of scion and rootstock varieties.

\section{References}

1. N. Ollat, L. Bordenave, J.P. Tandonnet, J.M. Boursiquot, E. Marguerit, Acta Hortic., 1136, 11-22 (2016) URL: https://doi.org/10.17660/ActaHortic.2016.1136.2

2. S. Tedesco, A. Pina, P. Fevereiro, F. Kragler, Agronomy, 10, 706 (2020) https://doi.org/10.3390/agronomy 10050706

3. A. Sabir, JFST., 8(6), 1681-1692 (2016) https://doi.org/10.3390/agronomy10060862

4. A. A. Elaidy, A. M. Khalf, Atef Abo-Ogiala, The Middle East Journal, 8(1), 167-175 (2019) https://www.researchgate.net/publication/316307009_ROOTSTOCK- (Last accessed 22.07.2020)

5. M. Di Filippo, V. Hernán, Journal International des Sciences de la Vigne et du Vin, 45, 75-84 (2011) https://oeno-one.eu/article/view/1487 (Last accessed 26.07.2020)

6. J. B. Oliveira, R. Egipto, O. Laureano, R. de Castro, LWT- Food Science and Technology, 14, 108415 (2019) https://doi.org/10.1016/j.lwt.2019.108415

7. A. Miele, L. Antenor Rizzon, RBF, 41(3), (2019) https://doi.org/10.1590/010029452019138

8. P. Coelho de Souza Leão, A. Rodrigues de Melo, C. Ciênc. agrotec., 43, Lavras 01 (2019) https://doi.org/10.1590/1413-7054201943005719

9. A. Miele, L. Antenor, Rizzon Rev. Bras. Frutic., 41(3), Jaboticabal (2019) https://doi.org/10.1590/0100-29452019138

10. B. Köse, Eur. J. Hortic. Sci., 79(4), 197-202 (2014) https://www.researchgate.net/publication/284900218_(Last accessed 26.07.2020)

11. D. Vijaya, V. Joshi, G. R. Reddy, D. A. Kumari, Agric. Res., 56(1), 84-91 (2019) DOI: 10.5958/2395-146X.2019.00013.9

12. A. Gautier, S. J. Cookson, L. Lagalle, N. Ollat, E. Marguerit, OENO One., 54, 1-13 (2020) https://doi.org/10.20870/oeno-one.2020.54.1.2458

13. A. Zombardo, C. Crosatti, P. Bagnaresi, L. Bassolino, BMC Genomics, 21(1), (2020) DOI: $10.1186 / \mathrm{s} 12864-020-06795-5$

14. G. Gutiérrez Gamboa, E. Gomez-Plaza, A. Belén Bautista-Ortín, T. Garde-Cerdán, J. Sci. Food Agric. (2018) https://doi.org/10.1002/jsfa.9496

15. V. Mara, V. Kodiulović, J. Raičević, A. Gazivoda, M. Peri_ić, Acta Hortic., 1136, 4550 (2016) https://doi.org/10.17660/ActaHortic.2016.1136.7

16. J. B. Oliveira, R. Egipto, O. Laureano, R. de Castro LWT- Food Science and Technology, 114, 108415 (2019) https://doi.org/10.1016/j.lwt.2019.108415

17. M. Carrasco-Quiroz, A. M. Martínez-Gil, G. G. Gamboa, Y. M Moreno, J SCI FOOD AGR, 100(8), 3517-3524 (2020) https://doi.org/10.1002/jsfa.10395 